\title{
Meningioma in Lateral Cerebellomedullary Cistern without Dural Attachment
}

\author{
Prithvi Varghese $^{1}$ Julio Chacko Kandathil ${ }^{2}$ Jayasree Govindan ${ }^{3}$ Rashmi R. ${ }^{3}$ \\ Muhammed Jasim Abdul Jalal ${ }^{4}$ \\ ${ }^{1}$ Department of Neurosurgery, VPS Lakeshore Hospital, Kochi, \\ Kerala, India \\ ${ }^{2}$ Department of Radiology, VPS Lakeshore Hospital, Kochi, \\ Kerala, India \\ ${ }^{3}$ Department of Pathology, VPS Lakeshore Hospital, Kochi, \\ Kerala, India \\ ${ }^{4}$ Department of Internal Medicine and Rheumatology, VPS \\ Lakeshore Hospital, Kochi, Kerala, India \\ Indian J Neurosurg 2017;6:144-148. \\ Address for correspondence Muhammed Jasim Abdul Jalal, MBBS \\ DNB, Department of Internal Medicine and Rheumatology, VPS \\ Lakeshore Hospital, Kochi, Kerala 682040, India \\ (e-mail: jasimabduljalal@yahoo.com).
}

\begin{abstract}
Keywords

- meningioma

- lateral medullary cisternal meningioma

- meningioma without dural attachment

Intracranial meningiomas without dural attachment are rare and posterior cranial fossa meningiomas without dural attachment are rarer. Such meningiomas are thought to arise from arachnoid cap cells in pial membrane, tela choroidea, or choroid plexus. MRI is the best imaging modality for the diagnosis of meningiomas and typically shows an enhancing, dural based, extra-axial soft tissue mass with a characteristic dural tail. Meningioma without dural attachment should be suspected if the MRI shows a space-occupying lesion having features of a meningioma but without a dural base and dural tail. We report a case of meningioma in the lateral cerebellomedullary cistern without dural attachment.
\end{abstract}

\section{Introduction}

Meningiomas are neoplasms believed to arise from meningothelial (arachnoidal cap) cells. Typically a meningioma is a dural-based tumor with a broad attachment. Rarely intracranial meningiomas can develop without a dural attachment. Such tumors are mostly seen in intraventricular regions, pineal region, sylvian fissure, and subcortical areas. ${ }^{1}$

Meningiomas of posterior cranial fossa (PCF) constitute $9 \%$ of all intracranial meningiomas. Only few cases of PCF meningiomas without dural attachment have been reported (-Table 1). Here, we report a rare case of PCF meningioma located in the lateral cerebellomedullary cistern, having no dural attachment.

\section{Case Report}

\section{History}

A 36-year-old Indian man presented with dull aching neck pain of 4 years duration. The patient also experienced episodes of

received

November 27, 2016

accepted

March 25, 2017

published online

May 9, 2017 DOI https://doi.org/
10.1055/s-0037-1602754.
ISSN 2277-954X. slurred speech and unsteadiness of gait for the last 2 months. There were no significant past illnesses. The patient was hemodynamically stable. He was conscious, oriented, and the pupils were equal and reactive to light. There were no motor deficits. All the deep tendon reflexes were normal. The plantar responses were flexor bilaterally. Minimal cerebellar signs could be elicited, and the tandem walking was impaired. All other systems were within normal limits.

\section{Investigations}

Laboratory investigations including hemogram, renal function, liver function, and coagulation profile were within normal limits.

\section{Imaging}

Magnetic resonance imaging (MRI) of the brain (-Fig. 1) showed a 3- $\times 4-\mathrm{cm}$, well-circumscribed, extra-axial, lobulated, iso- to hypointense (T1), contrast-enhancing mass in left cerebellomedullary cistern with a slight extension below the foramen magnum. Mass effect was

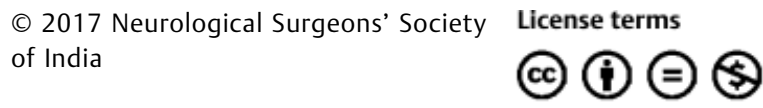


Table 1 Case series/case reports posterior fossa meningiomas without dural tail

\begin{tabular}{|l|l|l|l|}
\hline S. No. & Author & Site & Year \\
\hline 1. & Abraham and Chandy $^{2}$ & Fourth ventricle & 1963 \\
\hline 2. & Hoffman et al $^{3}$ & Fourth ventricle & 1972 \\
\hline 3. & Gökalp et al $^{4}$ & Fourth ventricle & 1981 \\
\hline 4. & Tsuboi et al $^{5}$ & Fourth ventricle & 1983 \\
\hline 5. & Cantore et al $^{6}$ & Inferior tela choroidea & 1986 \\
\hline 6. & Shibuya et al $^{7}$ & Lateral cerebellomedullary cistern & 1999 \\
\hline 7. & Nicoletti et al $^{8}$ & Cisterna magna & 2001 \\
\hline 8. & Akimoto et al $^{9}$ & Fourth ventricle & 2001 \\
\hline 9. & Miranda et al & Intraventricular & 2009 \\
\hline 10. & Kim et al $^{11}$ & Lateral cerebellomedullary cistern & 2010 \\
\hline 11. & Present case & $\begin{array}{l}\text { Lateral cerebellomedullary } \\
\text { cistern }\end{array}$ & 2017 \\
\hline
\end{tabular}

noted on the medulla, left cerebellar hemisphere, and upper cervical cord. Because of the mass effect, obstruction was seen at level of outlet of fourth ventricle, with mild dilation of lateral, third, and fourth ventricles.

\section{Surgery}

A left retromastoid suboccipital craniotomy inclusive of the foramen magnum with total excision of space-occupying
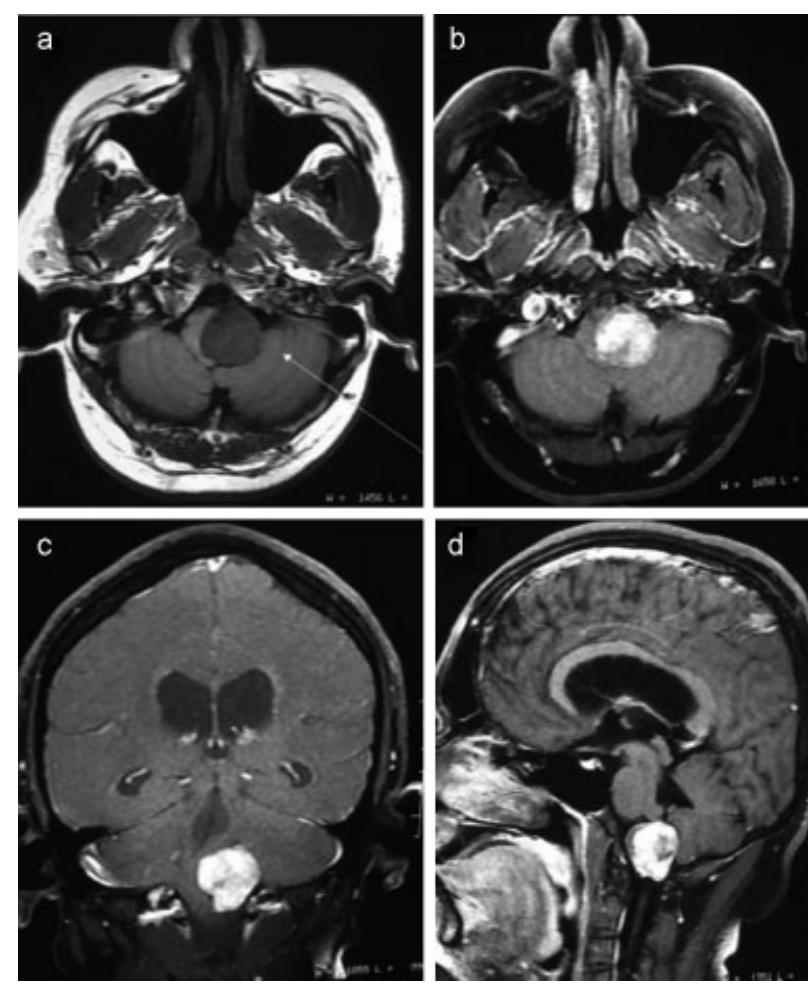

Fig. 1 MRI of the brain, showing well circumscribed, T1 iso- to hypointense left cerebellomedullary cistern meningioma. Medulla and upper cervical cord displaced to left and compressed. Mass effect also seen on left cerebellar hemisphere. (a) Axial T1 image; (b) Axial postcontrast T1FS image; (c) Coronal postcontrast T1FS image: obstruction noted at outlet fourth ventricle with mild lateral third and fourth ventricle dilation. (d) Sagittal postcontrast T1FS image. lesion in the lateral cerebellomedullary cistern was done. At surgery dura appeared tense. The tumor was extra-axial, encapsulated, firm in consistency, moderately vascular, and extended from the level of internal acoustic meatus to just beyond foramen magnum. The lower cranial nerve rootlets were displaced anteriorly by the tumor ( - Fig. 2). Left posterior inferior cerebellar artery was adherent to the capsule of the tumor at its posterior aspect. Brainstem was displaced laterally. Even though the tumor was adherent to the dura over the adjacent occipital bone, it was not attached to occipital and could be separated. However, the tumor was firmly attached to arachnoid at the lateral aspect of brainstem near the foramen of Luschka.

There were no intraoperative complications or postoperative neurological deficits. The cerebellar signs and gait improved postoperatively.

\section{Histopathology and Immunohistochemistry}

$\mathrm{H}$ and $\mathrm{E}$ sections (-Fig. 3) showed the neoplasm as composed of small whorls of syncytial polyhedral cells with no significant atypia/mitotic activity, embedded in a collagenous matrix, admixed with psammoma bodies. The neoplastic cells coexpressed vimentin and EMA, with a high $\mathrm{K}_{\mathrm{i}}-67$ proliferative index of $15 \%$ in areas. Hence the neoplasm

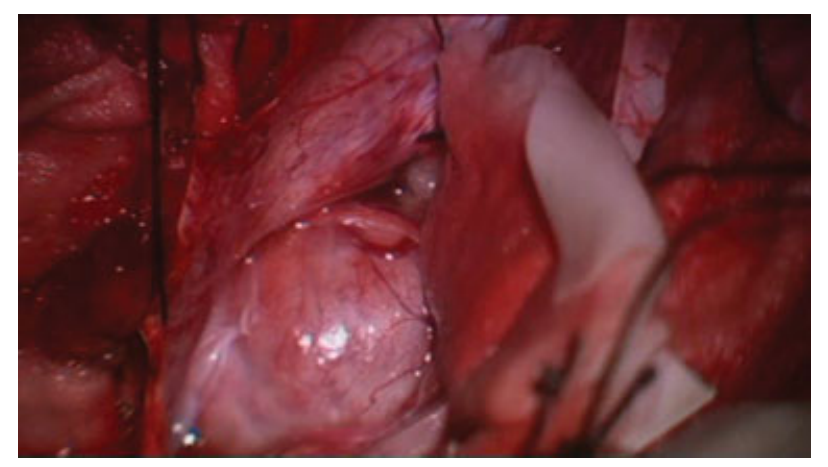

Fig. 2 Intraoperative view. Extra-axial, encapsulated, firm, moderately vascular tumor displacing the lower cranial nerve rootlets anteriorly. 

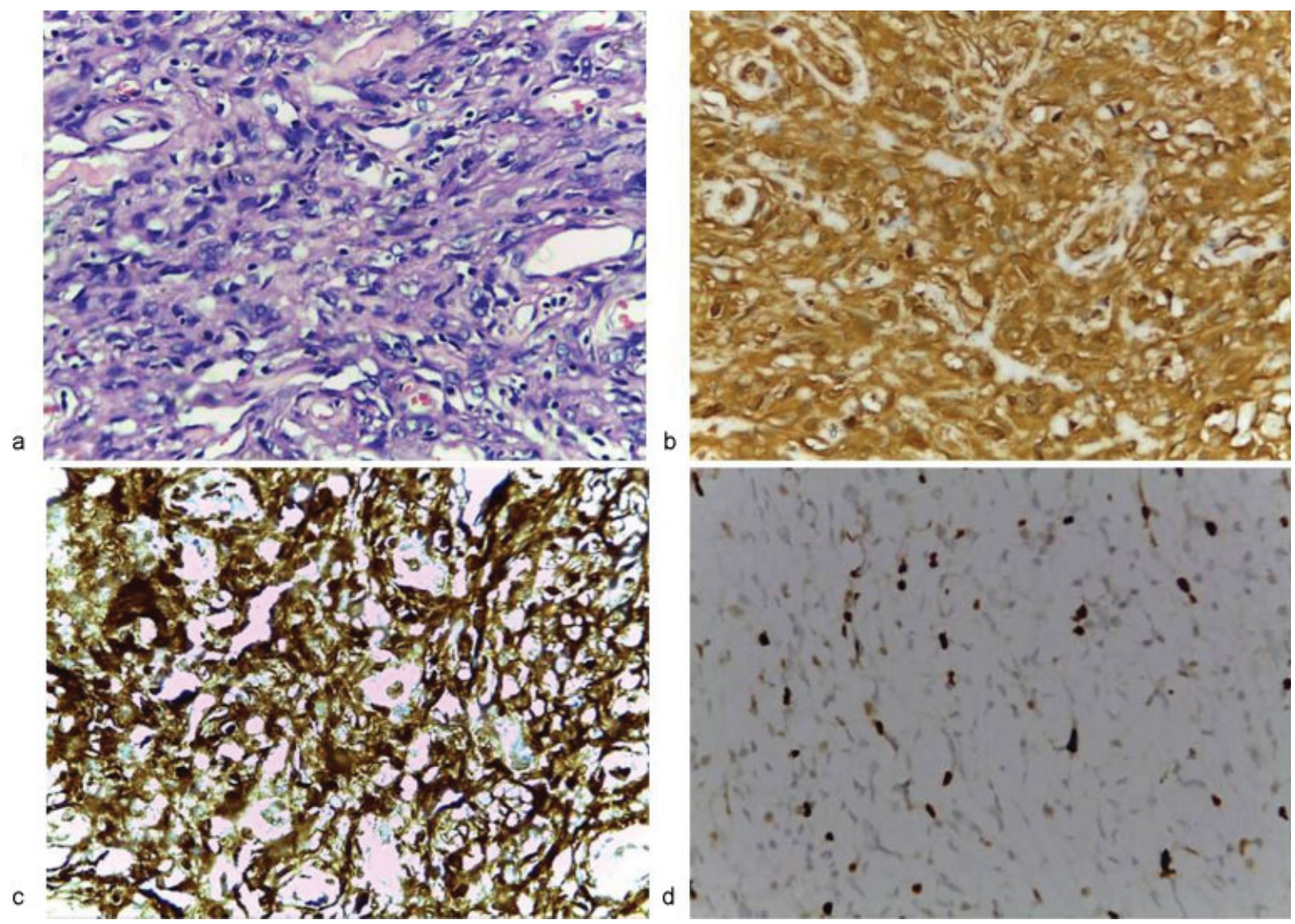

Fig. 3 Histopathology and immunohistochemistry. (a) High-power view (x40) H\&E sections showing neoplastic meningothelial cells. (b) Neoplastic meningothelial cells positive for vimentin. (c) Neoplastic meningothelial cells positive for vimentin EMA (epithelial membrane antigen). (d) Neoplastic meningothelial cells with ki-67 proliferation index-12\%.

was categorized as the World Health organization (WHO) grade II meningioma (transitional type).

\section{Follow-up}

Postoperative contrast-enhanced MRI of the brain (-Fig. 4) did not show any evidence of residual tumor.

\section{Discussion}

Meningiomas are slow-growing tumors thought to originate from the arachnoid cap cells of the meninges. Typically a meningioma has a broad dural attachment. However, intracranial meningiomas can arise without a dural
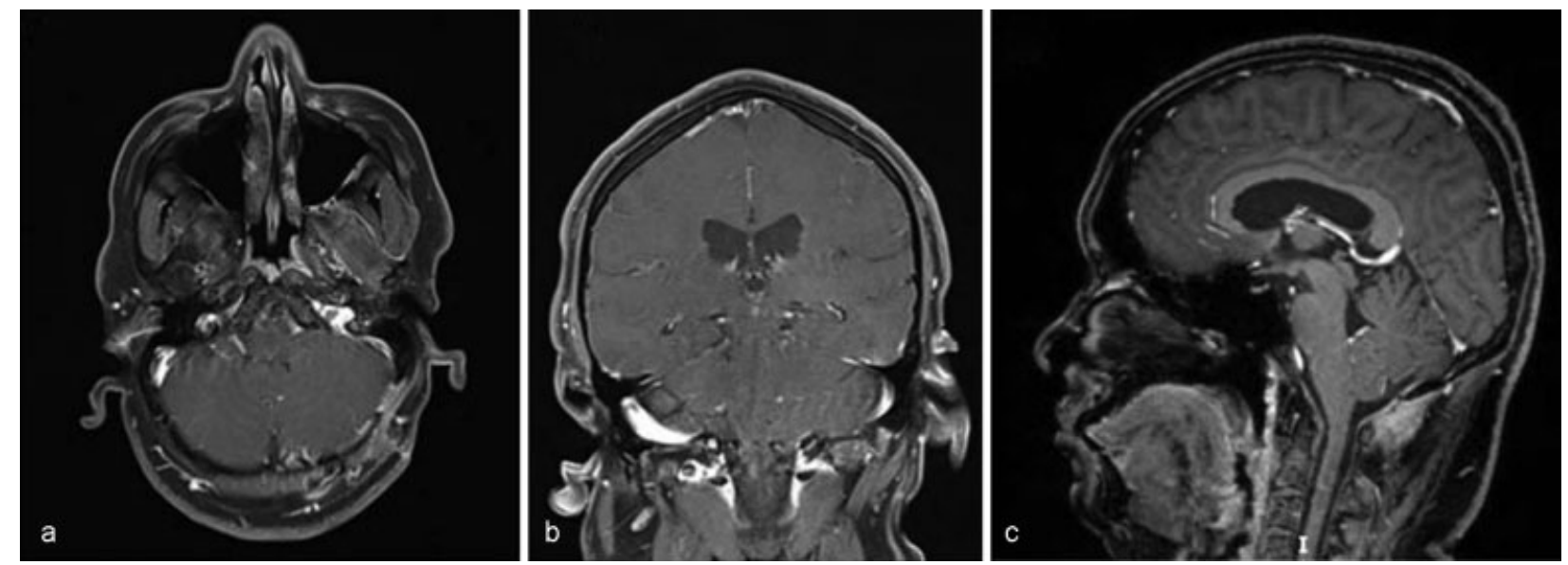

Fig. 4 Postoperative MRI of the brain. (a) Axial postcontrast T1FS image showing left suboccipital craniotomy with no residual tumor at left cerebellomedullary angle tumor site. (b) Coronal postcontrast T1FS image showing left suboccipital craniotomy with no residual tumor at left cerebellomedullary angle tumor site. (c) Sagittal postcontrast T1FS image showing left suboccipital craniotomy with no residual tumor at left cerebellomedullary angle tumor site. 
attachment. Meningiomas without dural attachment are thought to arise from arachnoid cap cells in pial membrane, tela choroidea, or choroid plexus. Intracranial meningiomas without dural attachment are rare and PCF meningiomas without dural attachment are rarer.

Meningiomas of the PCF without dural attachment have been classified in 1963 by Abraham and Chandy ${ }^{2}$ into the following three categories:

1. Meningiomas arising from the choroid of the fourth ventricle and lying wholly within it

2. Meningiomas arising from the inferior tela and lying partly in the fourth ventricle and partly in the cerebellar hemisphere

3. Meningiomas lying in the cisterna magna

In 1999, Shibuya et $\mathrm{al}^{7}$ reported a case of meningioma in the lateral cerebellomedullary cistern without dural attachment but arising from the choroid plexus out of the lateral recess. In 2010, Kim et al reported another case of meningioma in lateral cerebellomedullary cistern without dural attachment. ${ }^{11}$

Thirty-six cases of PCF meningiomas without dural attachment have been reported so far. Twenty-seven of these were intraventricular meningiomas, four arose from the inferior tela choroidea, three were found in the cisterna magna, and two in the lateral cerebellomedullary cistern. The case reported here is the third case of a meningioma in lateral cerebellomedullary cistern without dural attachment.

Preoperative diagnosis of posterior fossa meningioma without dural attachment is difficult. It should be differentiated from the commonly encountered tumors such as ependymoma and medulloblastoma. Posterior fossa meningioma without dural attachment are hyperdense to the adjacent brain with smooth contours, good demarcation, and rare calcification on computed tomography (CT). ${ }^{11}$ Ependymomas show irregular enhancement and are markedly heterogenous due to hemorrhage, cystic components, calcification, or necrosis. ${ }^{12}$ On CT, medulloblastomas appear as a hyperdense mass arising from the vermis. ${ }^{13}$ They do not usually extend into the basal cisterns.

MRI is the best imaging modality for the diagnosis of meningiomas and typically shows an enhancing, duralbased, extra-axial soft tissue mass with a characteristic dural tail. ${ }^{14}$ On T1-weighted images meningiomas are iso-hypointense to gray matter. On T2-weighted images meningiomas are iso-hyperintense to gray matter. Calcified meningiomas appear hypointense to gray matter on T2-weighted images. ${ }^{15}$

The treatment of choice for a symptomatic meningioma is surgical excision. The objective of surgery is total removal of the meningioma, including the dural attachment and involved bone. Simpson classified the types of excision of meningiomas into five grades and found that recurrence rates increased significantly with the grade of excision. ${ }^{16}$ Because the meningioma discussed here had no dural attachment and was totally excised, it may be considered equivalent to the Simpson grade 1 excision.
$\mathrm{K}_{\mathrm{i}}-67$ and MIB1 are monoclonal antibodies directed against different epitopes of same proliferation-related antigen (i.e., $\mathrm{K}_{\mathrm{i}}$-67-related protein). Integration of the Simpson's grade of surgical excision with histopathology and proliferation marker studies such as MIB1 and $\mathrm{K}_{\mathrm{i}}-67$ labeling index can increase the accuracy in predicting recurrences. ${ }^{17}$

In the case presented here, a total excision was achieved without the need to remove the dura and hence can be considered equivalent to Simpson's grade 1 excision. However, because the $\mathrm{K}_{\mathrm{i}}-67$ proliferative index is high, the patient has to be followed up closely with contrastenhanced MRI scans periodically.

\section{Conclusion}

PCF meningiomas without dural attachment are rare. Such meningiomas can be suspected if MRI shows a spaceoccupying lesion having features of a meningioma but without a dural base and dural tail. The treatment of choice for such a meningioma is total surgical excision.

Funding
None.

Financial Disclosure

The authors have no financial relationships relevant to this article to disclose.

Conflict of Interest

The authors have no conflict of interest relevant to this article to disclose.

\section{References}

1 Velho V, Agarwal V, Mally R, Palande DA. Posterior fossa meningioma "our experience" in 64 cases. Asian J Neurosurg 2012;7(03):116-124

2 Abraham J, Chandy J. Meningioma of the posterior fossa without dural attachment: a case report. J Neurosurg 1963;20:177-179

3 Hoffman JC Jr, Bufkin WJ, Richardson HD. Primary intraventricular meningiomas of the fourth ventricle. Am J Roentgenol Radium Ther Nucl Med 1972;115(01):100-104

4 Gökalp HZ, Ozkal E, Erdogan A, Selcuki M. A giant meningioma of the fourth ventricle associated with Sturge-Weber disease. Acta Neurochir (Wien) 1981;57(1-2):115-120

5 Tsuboi K, Nose T, Maki Y. Meningioma of the fourth ventricle: a case report. Neurosurgery 1983;13(02):163-166

6 Cantore G, Ciappetta P, Delfini R, Raco A. Meningiomas of the posterior cranial fossa without dural attachment. Surg Neurol 1986;25(02):127-130

7 Shibuya M, Koketsu N, Osuka K. A meningioma of the lateral cerebellomedullary cistern without dural attachment. J Clin Neurosci 1999;6(01):50-52

8 Nicoletti GF, Platania N, Albanese V. Meningioma within the cisterna magna without dural attachment. Case report. J Neurosurg Sci 2001;45(03):185-187

9 Akimoto J, Sato Y, Tsutsumi M, Haraoka J. Fourth ventricular meningioma in an adult-case report. Neurol Med Chir (Tokyo) 2001;41(08):402-405 
10 Miranda P, Simal JA, Vila M, Hernández M, Menor F, Alvarez-Garijo JA. Posterior fossa clear cell meningioma without dural attachment in a child. Childs Nerv Syst 2009;25(03):389-392

11 Kim SM, Jung SS, Park MS, Park KS. Meningioma in the lateral cerebellomedullary cistern without dural attachment. J Korean Neurosurg Soc 2010;47(06):464-466

12 Smith AB, Smirniotopoulos JG, Horkanyne-Szakaly I. From the radiologic pathology archives: intraventricular neoplasms: radiologic-pathologic correlation. Radiographics 2013;33(01):21-43

13 Taylor MD, Northcott PA, Korshunov A, et al. Molecular subgroups of medulloblastoma: the current consensus. Acta Neuropathol 2012;123(04):465-472
14 Matsushima N, Maeda M, Takamura M, Matsubara T, Taki W, Takeda K. MRI findings of atypical meningioma with microcystic changes. J Neurooncol 2007;82(03):319-321

15 Ginsberg LE. Radiology of meningiomas. J Neurooncol 1996; 29(03):229-238

16 Simpson D. The recurrence of intracranial meningiomas after surgical treatment. J Neurol Neurosurg Psychiatry 1957;20(01): 22-39

17 Perry A, Louis DN, Scheithauer BW, Budka H, Deimling VA. Meningiomas. In: Louis DN, Ohgaki $\mathrm{H}$, Wiestler OD, Cavenee WK, eds. World Health Organization Classification of the Central Nervous System; 2007:164-172 